\title{
National Survey of Hospital Medication Safety Practice during Mass Gathering (Hajj-2016) in Makka, Saudi Arabia: Medication Administration
}

\author{
Yousef Ahmed Alomi ${ }^{1 *}$, Nezar Adnan Yahya Khayat², Mustafa Jamil Baljoon², Yasir Abdulraheem \\ Bamagaus $^{3}$, Hani Mohammed Ali Jumah ${ }^{3}$ \\ ${ }^{I}$ The Past General Manager of General Administration of Pharmaceutical Care and Head, National Clinical \\ pharmacy, pharmacy practice and Pharmacy $R \& D$ Administration, Ministry of Health, Riyadh, KSA
}

${ }^{2}$ General Director, Makka Health Affairs Region, Makha, KSA

${ }^{3}$ Pharmaceutical Care Administration, Makka Medical Affairs Region, Makha, KSA

Received: 13 August 2017;
Accepted: 28 September 2017

*Correspondence to:

Dr. Yousef Ahmed Alomi, The Past General Manager of General Administration of Pharmaceutical Care,Head, National Clinical pharmacy, and Pharmacy practice, and Pharmacy $R \& D$ Administration, Ministry of Health, Riyadh 11392, Kingdom of Saudi Arabia (KSA) Email:yalomi@gmail.com

Copyright: $\odot$ the author(s),publisher and licensee Indian Academy of Pharmacists. This is an openaccess article distributed under the terms of the Creative Commons Attribution Non-Commercial License, which permits unrestricted non-commercial use, distribution, and reproduction in any medium, provided the original work is properly cited.

\section{Abstract}

Objective: To explore the national survey of hospital medication safety practice during mass gathering (Hajj -2016) in Makkah, Saudi Arabia: Medication Administration, the finding of ISMP (2011) self-assessment of medication safety at the hospital. Methods: It is 15 days crosssectional national survey of hospital medication safety at Makkah region. The survey modified from Institution of Safe Medication Practice (ISMP) self-assessment of hospital medication safety. It consisted of a demographic section and ten domains with 270 questions. The ten areas included patient information, drug information, communication of medication orders, drug preparation, medication distribution, medication devices, work environment, staff competency, patient education, quality process with risk management domain. The 5-points Likert response scale system used. The survey distributed to sixteen directors of hospital pharmacy during mass gathering Hajj-2016. The medications safety officer at Makkah region distributed the questionnaire and made a follow-up on a daily basis used physical visiting and through the telephone call. Results: The survey distributed to sixteen hospitals, the response rate, was eleven hospitals (68.75\%). The total score of all ISMP-self assessment of medication safety was $3.39+/-0.51$ (67.68 \%) with $\mathrm{Cl}(3.2-3.6) \mathrm{P}<0.05$. The medication administration included two domains; drug standardization, storage, and distribution with scores 3.54 (71.8\%), Medication devices acquisition, Use, and monitoring with scores 2.97 (59.4\%). The highest score will all section was Antidotes for medications with guidelines use readily available 4.8 (96\%). The lowest score was all electronic infusion pump full functionality to intercept and prevent wrong dose/wrong infusion rate errors $2.33(46.6 \%)$. Conclusion: The standardized medication process during administration including ready-made preparations, fixed drug concentration, and standardized medication devices required during mass gathering Hajj period. The annual survey of medication administration safety with practical tools is potential to prevent any drug-related errors will create medication safety culture and avoid burden mistakes on health care system during mass gathering Hajj period in Makka, Saudi Arabia.

Key words: Medication Safety, Hajj, Drug, Administration, Ministry of Health, Saudi Arabia.

\section{INTRODUCTION}

Medication management and use consisted of drug procurement, drug prescribing, drug 
preparation, medication dispensing, drug administration, and drug monitoring. The possibility of medication events occurrence for each event. Most of the medication errors reported in Saudi Arabia during drug prescribing and dispensing and seldom find a bout a drug administration. ${ }^{[1-5]}$ In practice, the majority detected and reported by a pharmacist. The pharmacist is aware of all stages except the drug administration. Most of the time the pharmacist spent much time in pharmacy department with drug requisition, preparation, dispensing, prescribing, and drug monitoring. The drug administration errors can notify by nurses. Also, with special situations like mass gathering hajj time, the nurses very busy with all pilgrims with drug administration and the possibility of committing errors is high. The nurse prepare the medication for administration like intravenous bolus intravenous infusion; those preparations had the various concentration for each drug, the nurse faced problems with remembering all concentration for different medication concentration; this factor may lead to committing an error. The general administration of pharmaceutical care published medication dilution manual for appropriate concentrations to adults, pediatrics, and neonates. ${ }^{[6-8]}$ In one local study, the authors found number administration errors was 38 report only within 24 months period, the most errors were missed medications $39.5 \%$, and expired medication 15.8 $\%$. The most errors occurred at Pediatric medicine unit. ${ }^{[9]}$ Another study through survey asked the nurses about administration errors the author found that the number of administration errors was 1.4 time daily and most common type of errors was the wrong time of medication 30.9\%. ${ }^{[10]}$ There is no study discussed all medication safety culture or places at the nursing department, may be the Institution Safe Medication Practice (ISMP) self-assessment medication safety at hospitals revised all medication management and use process including drug administration safety culture. In the finding of ISMP self-assessment of medication safety, the two studies done in the 2000s and 2011s report the total average score of medicines safety was from $56 \%$ to $71 \%$. The key elements of drug standardization, storage and distribution improved from $73 \%$ to $81 \%$, and medication devices acquisition, use changed from $69 \%$ to $70 \%{ }^{[11,12]}$ The authors not familiar with any investigations of drug administration by using ISMP self-assessment tools in Saudi Arabia before, or Gulf and Middle East countries with emphasis during mass gathering hajj period. The objective of this report to explore the national medication safety practice during mass gathering (Hajj-2016) in Makkah hospitals, Saudi Arabia: medication administration, the finding of ISMP (2011) self-assessment of medication safety at the hospital.

\section{METHODS}

It is a fifteen days cross-sectional national survey of hospital medication safety at Makkah region. The survey modified from Institution of Safe Medication Practice (ISMP) self-assessment of hospital medication safety. It consisted of a demographic section and ten domains with 270 questions. The ten areas included patient information, drug information, communication of drug orders and other drug information, drug Labeling and Packaging and Nomenclature, drug standardization, storage and distribution, medication devices acquisition, use, and monitoring, environmental factors, workflow, and staffing, staff competency. The patient education, quality processes and risk management domain. It contained a twenty core sections included essential patient information, essential drug information, a controlled drug formulary system, methods of communicating drug orders. The strategies to minimize the possibility of errors, clear labels that identify drugs are on all drug containers, standardized of IV solutions, drug concentrations, doses, and administration times. A safety-supportive culture, practitioners are stimulated to detect and report adverse events, errors, hazards, and observed at risk behavior, and redundancies that support a system of independent double check at risk. The practitioners receive sufficient orientation to medication use; the practitioners involved in medication use provided with ongoing education about medication error prevention and the safe use, patients, are included as active partners. Medications provided to patient care units safely and securely, the unit stock, is restricted, hazardous chemicals safely sequestered, the potential for human errors, medications are prescribed, transcribed, prepared, dispensed, and administered within an efficient and safe workflow. The complement of qualified, well-rested practitioners matches the clinical workload without compromising patient safety. The 5-points Likert response scale system used. The scoring key identified as number (1) equal to (A): No activity to implement, (2) equal to (B): Considered, but not implemented, (3) equal to (C): partially implemented in some or all areas. (4) Equal to (D): Fully implemented in some areas, and (5) equal to (E): Fully implemented throughout. The survey conducted at a permanent and temporary hospital located at Makkah and holy places. Most of the hospital had outpatient, and emergency services, some of them had critical care section for adults, pediatrics, and internal medicine. The hospital provided emergency and outpatient pharmacies, inpatient pharmacies. Some of the hospitals had intravenous admixture 
and total parenteral services and drug information services. Structural Clinical pharmacy services missed at most of the hospitals except critical care pharmacy and stewardship antimicrobial program at permanent hospitals, some essential Clinical pharmacy program; pain management, and anticoagulation program not existed at all hospital. The survey distributed to directors of hospital pharmacy during mass gathering Hajj-2016. The medications safety officer at Makkah region distributed the questionnaire and made follow up on a daily basis used physical visiting and through the telephone call. The study made as an electronic format, and it analyzed through survey monkey system and Microsoft Excel version ten. The authors suggested some solution to improve the scoring medication safety culture and the finding of ISMP self-assessment, the 5-points Likert scale system with high priority or opportunity to implement (5) and low priority or opportunity to implement (1). Those suggestions based on General Administration of Pharmaceutical strategic goals and Saudi Central Board of Accreditation for Health Care Institutions (CBAHI) standards in Saudi Arabia. The ten domains divided into for several parts for analysis, discussion, and solutions. Part one: patient information, part two: drug information, part three: medication preparation and dispensing (communication of drug orders and other drug information, drug Labeling and Packaging and Nomenclature). The part four: medication administration (drug standardization, storage and distribution, medication devices acquisition, use, and monitoring), part five: environmental factors, workflow, and staffing, staff competency, and part six: patient education, quality processes, and risk management. The study explored the part number four; it is a finding from ISMP (2011) medication safety at a hospital in Makkah.

\section{RESULTS}

The survey distributed to sixteen hospitals, the response rate, was eleven hospitals $(68.75 \%)$. The number of permanent hospitals was six (54.45\%) located at Makka city while the temporary hospitals were five $(45.45 \%)$ located at holy places. Of those four (36.4\%) hospitals bed size was (100-199) and 3 (27.3\%) bed size (200-299). The number of hospitals accredited by Saudi Central Board of Hospitals Accreditation (CIBAHI) was four (36.4\%) while three hospitals $(27.3 \%)$ accredited by USA International Joint Commission and CIBAHI. The total number of prescriptions was $(120,598)$. Of those $(72,627)$ were Ambulatory care prescriptions, while $(43,242)$ were Emergency Prescriptions, and $(4,729)$ were inpatient orders. The total number of the pharmacist was (180) while pharmacy technician (83) and some clinical pharmacists not reported as explored in Table 1. The total score of all ISMP-self assessment of medication safety was $3.39+/-0.51(67.68 \%)$ with CI (3.2-3.6) $\mathrm{P}<0.05$ and range $(2.75-3.93)$. The average score of drug standardization, storage and distribution domain at all hospital were 3.54+/- $0.5(70.8 \%)$ with CI (3.37-3.71), $\mathrm{P}<0.05$ and range $(2.73-4.80)$. The average score Medication Devices acquisition, Use, and Monitoring domain at all hospital were $2.97+/-$ $0.45(59.40 \%)$ with CI $(2.76-3.18), \mathrm{P}<0.05$ and range $(2.33-3.78)$ as explored in table 2 . The highest score of the drug standardization, storage, and distribution key element was a Standard time for scheduled drug administration established and consistently used 4.40 $(88 \%)$ while the lowest score Bulk chemicals in the pharmacy routinely assessed 2.73 (54.6\%), and all detail results with all cores explored in table 3 . The highest score of Medication Devices acquisition key element was the Practitioners educated about medical devices and associated protocols/guidelines; and competency with their use $3.78(75.6 \%)$. The lowest score was the smart infusion pump technology used, the percent of infusions with medications that administered using the full functionality of the safety software monitored 2.33 $(46.6 \%)$ as explored in Table 4.

\section{DISCUSSION}

The ministry of health with an emphasis on logistic department started the implementation of $\mathrm{MOH}$ strategic plan in 2012. ${ }^{[13]}$ The department tries brought the best equipment to each hospital unit with a focus on medical devices or equivalent. One of the critical units was nursing. That unit needs medication administration devices for smart infusion pump and regular pump; patient controlled analgesia pump, intravenous infusion set, syringes with the different size the logistic department make electronic internally website network to list of equipment and nonequipment devices and instrument for nursing units. The general administration of nursing can add or update any devices through the site. The logistic department arranged all the required equipment and medical devices to all hospitals including the holy places and Makka city with emphasis during mass gathering hajj period. All medication devices required standardized fixed configuration with appropriate drug concentration. The general administration of Pharmaceutical Care had planned to arrange all drug concentration based on Adult, pediatric, neonates 


\begin{tabular}{|c|c|c|c|c|c|c|c|c|c|c|c|c|c|c|}
\hline \multirow[b]{2}{*}{ 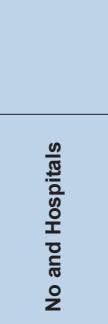 } & \multirow[b]{2}{*}{ 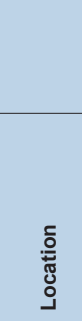 } & \multirow[b]{2}{*}{ 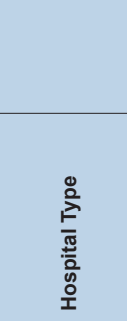 } & \multirow[b]{2}{*}{$\begin{array}{l}\frac{n}{8} \\
\Phi \\
\stackrel{0}{0} \\
\vdots \\
0 \\
2\end{array}$} & \multirow[b]{2}{*}{ 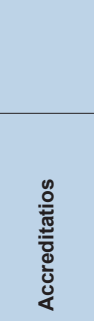 } & \multirow[b]{2}{*}{ 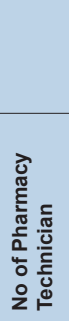 } & \multirow[b]{2}{*}{ 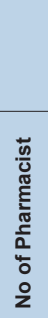 } & \multirow[b]{2}{*}{ 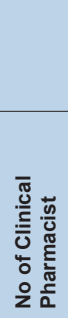 } & \multicolumn{2}{|c|}{$\begin{array}{l}\text { No of o O D } \\
\text { Prescriptions }\end{array}$} & \multicolumn{2}{|c|}{$\begin{array}{l}\text { No of Emergency } \\
\text { Prescriptions }\end{array}$} & \multicolumn{2}{|c|}{$\begin{array}{l}\text { No of Inpatient } \\
\text { Prescriptions }\end{array}$} & \multirow[t]{2}{*}{$\begin{array}{l}\text { Tot a } \\
N \text { o of } \\
\text { Prescrip- } \\
\text { tions }\end{array}$} \\
\hline & & & & & & & & 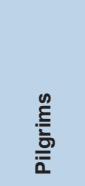 & 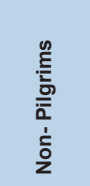 & 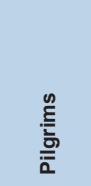 & 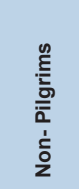 & $\frac{\stackrel{\mathscr{E}}{5}}{\frac{0}{\overline{0}}}$ & 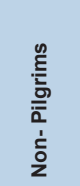 & \\
\hline 1.Mena-1 & Mena & Temporary & $100-199$ & Non & 9 & 1 & NR & 6,180 & 500 & 992 & 67 & 179 & 6 & \\
\hline 2. Mena-2 & Mena & Temporary & 100-199 & Non & 18 & 1 & NR & 15,203 & 330 & 1,661 & 113 & 612 & 17 & \\
\hline 3. Mena-3 & Mena & Temporary & 200-299 & Non & 19 & 2 & NR & 12,286 & 1,016 & 1,281 & 99 & 350 & 22 & \\
\hline 4. Arafat-1 & Arafat & Temporary & 200-299 & Non & 10 & 1 & NR & 527 & 73 & 272 & 22 & 129 & 6 & \\
\hline 5. Arafat-2 & Arafat & Temporary & 100-199 & Non & 8 & 1 & NR & 4,073 & 155 & 328 & 13 & 192 & 6 & \\
\hline 6. M-1 & Makka & Permanent & 300-399 & CIBAHI & 12 & 9 & NR & 22 & 650 & 244 & 6,135 & 31 & 664 & \\
\hline 7. M-2 & Makka & Permanent & 200-299 & $\begin{array}{c}\text { CIBAHI } \\
-\mathrm{JCI}\end{array}$ & 23 & 10 & NR & 34 & 3,208 & 185 & 9,408 & 46 & 728 & \\
\hline 8. M-3 & Makka & Permanent & $400-599$ & $\begin{array}{c}\text { CIBAHI } \\
-\mathrm{JCl}\end{array}$ & 60 & 24 & NR & 6,706 & 15,222 & 4,033 & 4,026 & 428 & 490 & \\
\hline 9. M-4 & Makka & Permanent & 50-99 & $\mathrm{JCl}$ & 7 & 2 & NR & 0 & 0 & 1,754 & 1,159 & 55 & 11 & \\
\hline 10. M-5 & Makka & Permanent & 100-199 & CIBAHI & 4 & 2 & NR & 1,037 & NR & 3,353 & NR & 29 & NR & \\
\hline 11. M-6 & Makka & Permanent & $300-399$ & CIBAHI & 10 & 30 & NR & 2,640 & 2,765 & 2,988 & 5,109 & 411 & 317 & \\
\hline Total & & & & & 180 & 83 & & 48,708 & 23,919 & 17,091 & 26,151 & 2,462 & 2,267 & 120,598 \\
\hline
\end{tabular}

\begin{tabular}{|c|c|c|c|c|c|c|c|c|c|}
\hline $\begin{array}{c}\text { Core } \\
\#\end{array}$ & Core Characteristic & $\begin{array}{l}\text { Mean } \\
\text { score }\end{array}$ & SD & Range & Percent & SD \% & $\underset{\%}{\operatorname{Range}}$ & $\begin{array}{c}\text { U S A, } \\
2000 \\
\text { Scores } \\
\quad \%\end{array}$ & $\begin{array}{c}\text { U S A, } \\
2011 \\
\text { Scores } \\
\%\end{array}$ \\
\hline v & Drug Standardization, Storage and Distribution & 3.54 & 0.50 & $2.73-4.80$ & 70.80 & 10.00 & $54.6-96$ & 73.00 & 81.00 \\
\hline 7 & $\begin{array}{l}\text { Standardized IV solutions, drug increase } \\
\text { concentrations, doses, and administration times }\end{array}$ & 3.65 & 0.416 & $3.20-4.40$ & 73.00 & 8.32 & $64-88$ & 71.00 & 88.00 \\
\hline 8 & $\begin{array}{l}\text { Safe, secure, and timely delivery of increase } \\
\text { medications to patient care units }\end{array}$ & 3.87 & 0.62 & $3.10-4.80$ & 77.40 & 12.4 & $62-96$ & 70.00 & 81.00 \\
\hline 9 & Restricted unit stock & 3.48 & 0.416 & $2.73-4.30$ & 69.60 & 8.32 & $54.6-86$ & 73.00 & 79.00 \\
\hline 10 & Hazardous chemicals safely sequestered & 3.01 & 0.40 & $2.73-3.60$ & 60.20 & 8.00 & $54.6-72$ & 86.00 & 79.00 \\
\hline VI & $\begin{array}{l}\text { Medication Devices acquisition, Use, and } \\
\text { Monitoring }\end{array}$ & 2.97 & 0.45 & $2.33-3.78$ & 59.40 & 9.00 & $46.6-75$ & 69.00 & 70.00 \\
\hline 11 & $\begin{array}{l}\text { Careful procurement, maintenance, use, increase } \\
\text { and standardization of devices }\end{array}$ & 2.97 & 0.45 & $2.33-3.78$ & 59.40 & 9.00 & $46.6-75$ & 69.00 & 70.00 \\
\hline
\end{tabular}

medication dilution manual of intravenous medication. ${ }^{[6,7-14]}$ The ISMP formulated self-assessment of medicines safety tools to assess all medication safety solution at all hospital department including medical devices. It is a unique and seldom to find this work in the world. The author did the study and measured medication safety of drug devices by using this tools. The results were less than Vaida AJ et al. study in 2000 and 2011. ${ }^{[11]}$ Those results were a normally found before the implementation of pharmacy strategic plan and drug devices with the fixed configuration not existed. Also, the general administration of Pharmaceutical Care with logistic department formulate corporate pharmacy and therapy committee for $\mathrm{MOH}$. Through the committee, ready-made prepare medication with fixed concentration added to $\mathrm{MOH}$ drug formulary especially high alter drug, and the committee added medication for cardiopulmonary resuscitation. ${ }^{[15]}$ The new project to make drug administration very easy and prevent any error during drug preparation or administration especially with very crowded time like mass gathering hajj period. There are several studies supported the standardized fixed drug concentration to use them regularly. ${ }^{[16-20]}$ The authors revised all key elements of medication administration safety, and they suggested several solutions to overcome all gap and weak point with the devices. For instance, use premixed fixed concentration medication use electronic smart infusion 


\begin{tabular}{|c|c|c|c|c|c|c|c|c|c|}
\hline \multicolumn{10}{|c|}{ V: Drug Standardization, Storage, and Distribution } \\
\hline \multirow[t]{3}{*}{$\begin{array}{c}\text { ISMP } \\
\text { No. }\end{array}$} & Key elements & $\begin{array}{l}A \\
1\end{array}$ & $\begin{array}{l}B \\
2\end{array}$ & $\begin{array}{l}C \\
3\end{array}$ & $\begin{array}{l}D \\
4\end{array}$ & $\begin{array}{l}E \\
5\end{array}$ & 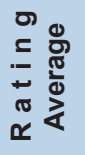 & 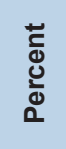 & 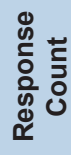 \\
\hline & $\begin{array}{l}\text { Core \# 7: Standardized IV solutions, increased drug concentrations, doses, and administration } \\
\text { times }\end{array}$ & & & & & & & & \\
\hline & The highest scores items & & & & & & & & \\
\hline 100 & Standard times for scheduled drug administration established and consistently used & 0 & 2 & 0 & 0 & 8 & 4.40 & 88 & 10 \\
\hline \multirow[t]{2}{*}{96} & $\begin{array}{l}\text { Concentrations for infusions of high-alert drugs such as morphine, heparin, insulin, and } \\
\text { vasopressors used for adult patients standardized to a single concentration }\end{array}$ & 2 & 1 & 0 & 1 & 7 & 3.91 & 78.2 & 11 \\
\hline & The lowest scores items & & & & & & & & \\
\hline 102 & $\begin{array}{l}\text { Standard order sets (electronic or preprinted) developed by gaining consensus among all } \\
\text { prescribers }\end{array}$ & 4 & 0 & 0 & 1 & 5 & 3.30 & 66 & 10 \\
\hline \multirow[t]{3}{*}{97} & $\begin{array}{l}\text { Concentrations for infusions of high-alert drugs such as morphine, heparin, insulin, and } \\
\text { vasopressors used for pediatric patients standardized to a single concentration }\end{array}$ & 4 & 0 & 1 & 0 & 5 & 3.20 & 64 & 10 \\
\hline & Core \# 8: Safe, secure, and timely delivery of increase medications to patient care units & & & & & & & & \\
\hline & The highest scores items & & & & & & & & \\
\hline 107 & $\begin{array}{l}\text { Antidotes and reversal agents for medications accompanying guidelines for emergency use } \\
\text { readily available near the point of use. }\end{array}$ & 0 & 0 & 0 & 2 & 8 & 4.80 & 96 & 10 \\
\hline \multirow[t]{2}{*}{106} & $\begin{array}{l}\text { Turnaround times for order verification and/or drug delivery from the pharmacy are consistent } \\
\text { with the time frames }\end{array}$ & 1 & 0 & 1 & 0 & 8 & 4.40 & 88 & 10 \\
\hline & The lowest scores items & & & & & & & & \\
\hline 104 & $\begin{array}{l}\text { Nurses are notified whenever first dose or stat medications are delivered to the unit when they } \\
\text { are not otherwise available on the unit (e.g., in an ADC). }\end{array}$ & 3 & 1 & 0 & 1 & 5 & 3.40 & 68 & 10 \\
\hline \multirow[t]{3}{*}{103} & $\begin{array}{l}\text { Sufficient numbers of ADCs, depending on their intended use installed in areas that are easily } \\
\text { accessible to staff and near patients }\end{array}$ & 4 & 0 & 1 & 1 & 4 & 3.10 & 62 & 10 \\
\hline & Core \# 9: Restricted unit stock & & & & & & & & \\
\hline & The highest scores items & & & & & & & & \\
\hline 111 & $\begin{array}{l}\text { All oral solid medications dispensed to patient care units in labeled, ready-to-use UNIT } \\
\text { DOSES. }\end{array}$ & 1 & 0 & 0 & 3 & 6 & 4.30 & 86.00 & 10 \\
\hline \multirow[t]{2}{*}{120} & $\begin{array}{l}\text { Pharmaceutical vendors and prescribers prohibited from distributing drug samples in inpatient } \\
\text { and outpatient areas }\end{array}$ & 2 & 0 & 0 & 1 & 7 & 4.10 & 82.00 & 10 \\
\hline & The lowest scores items & & & & & & & & \\
\hline 114 & The pharmacy fills all elastomeric pumps and prepares all IV solutions and irrigations needed & 5 & 0 & 0 & 1 & 4 & 2.90 & 58 & 10 \\
\hline \multirow[t]{3}{*}{113} & $\begin{array}{l}\text { IV solutions that are unavailable commercially are prepared in the pharmacy unless needed in } \\
\text { emergent life-saving situations. }\end{array}$ & 6 & 0 & 0 & 1 & 4 & 2.73 & 54.6 & 11 \\
\hline & Core \# 9: Hazardous chemicals safely sequestered & & & & & & & & \\
\hline & The highest scores items & & & & & & & & \\
\hline \multirow[t]{2}{*}{128} & $\begin{array}{l}\text { Containers of reagents used to test for fecal blood present in drug storage or preparation } \\
\text { areas, patient rooms, or patient bathrooms. }\end{array}$ & 3 & 0 & 1 & 0 & 6 & 3.60 & 72.00 & 10 \\
\hline & The lowest scores items & & & & & & & & \\
\hline \multirow[t]{2}{*}{125} & $\begin{array}{l}\text { Bulk chemicals in the pharmacy (for compounding) routinely assessed, and those that not } \\
\text { regularly used or considered dangerous eliminated from stock. }\end{array}$ & 6 & 0 & 0 & 1 & 4 & 2.73 & 54.6 & 11 \\
\hline & answered question 11 and skipped question 0 & & & & & & & & \\
\hline
\end{tabular}

\begin{tabular}{|c|c|c|c|c|c|c|c|c|c|}
\hline \multicolumn{10}{|c|}{ VI: Medication Devices acquisition, Use, and Monitoring } \\
\hline \multirow[t]{2}{*}{$\begin{array}{l}\text { I S M P } \\
\text { No. }\end{array}$} & $\begin{array}{l}\text { Key elements } \\
\text { Core 11: Careful procurement, maintenance, use, increase and } \\
\text { standardization of devices }\end{array}$ & $\begin{array}{l}E \\
1\end{array}$ & $\begin{array}{l}\mathrm{D} \\
2\end{array}$ & $\begin{array}{l}\mathrm{C} \\
3\end{array}$ & $\begin{array}{l}\text { B } \\
4\end{array}$ & $\begin{array}{c}\text { A } \\
5\end{array}$ & 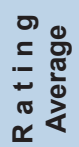 & 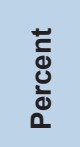 & 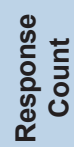 \\
\hline & The highest scores items & & & & & & & & \\
\hline 142 & $\begin{array}{l}\text { Practitioners educated about MEDICATION DEVICES (e.g., infusion pumps, automated } \\
\text { compounding equipment) }\end{array}$ & 2 & 0 & 1 & 1 & 5 & 3.78 & 75.60 & 9 \\
\hline
\end{tabular}




\begin{tabular}{|c|c|c|c|c|c|c|c|c|c|}
\hline 136 & $\begin{array}{l}\text { The types of enteral infusion pumps used in the hospital are limited to two or less (adult } \\
\text { and pediatric/neonatal pumps) and different from other infusion devices utilized in the } \\
\text { organization. }\end{array}$ & 2 & 0 & 0 & 2 & 4 & 3.75 & 75.00 & 8 \\
\hline \multirow[t]{2}{*}{135} & $\begin{array}{l}\text { The types of syringe pumps used in the hospital are limited to two or less to maximize } \\
\text { competency with their use. }\end{array}$ & 3 & 0 & 0 & 2 & 5 & 3.60 & 72.00 & 10 \\
\hline & The lowest scores items & & & & & & & & \\
\hline 148 & If SMART PUMP TECHNOLOGY used, the drug library updated via wireless technology. & 4 & 3 & 0 & 1 & 2 & 2.40 & 48.00 & 10 \\
\hline 144 & $\begin{array}{l}\text { PCA and syringe infusion pumps with SMART PUMP TECHNOLOGY with full functionality } \\
\text { employed to intercept and prevent wrong dose/wrong infusion rate errors }\end{array}$ & 5 & 1 & 0 & 1 & 2 & 2.33 & 46.60 & 9 \\
\hline 145 & $\begin{array}{l}\text { If SMART PUMP TECHNOLOGY used, the percent of infusions with medications that } \\
\text { administered using the full functionality of the safety software. }\end{array}$ & 5 & 1 & 0 & 1 & 2 & 2.33 & 46.60 & 9 \\
\hline
\end{tabular}

\begin{tabular}{|c|c|c|c|c|c|}
\hline No. & Strategic Goals & $\begin{array}{l}\text { C B A H I } \\
\text { standards }\end{array}$ & Suggestion for improvement during mass gathering Hajj & $\begin{array}{l}\text { Propriety } \\
\text { scores }\end{array}$ & $\begin{array}{l}\text { Opportunity } \\
\text { scores }\end{array}$ \\
\hline 1 & \multicolumn{5}{|c|}{ Pharmacy computerization } \\
\hline 1.1 & \multirow{5}{*}{ Strategic Goal 3} & \multirow{5}{*}{$\begin{array}{c}\text { MM.5 } \\
\text { MM.36 } \\
\text { MM.37 } \\
\text { MM.39 }\end{array}$} & $\begin{array}{l}\text { Implement full electronic complete medication administration records for inpatient } \\
\text { and outpatient pilgrim }\end{array}$ & 5 & 3 \\
\hline 1.2 & & & $\begin{array}{l}\text { Implement full electronic complete medication history for all outside and inside } \\
\text { Pilgrim before drug administration }\end{array}$ & 5 & 3 \\
\hline 1.3 & & & Use alerting system in CPOE during medication administration & 5 & 4 \\
\hline 1.4 & & & $\begin{array}{l}\text { Full implementation of medication administration of high alert complication and } \\
\text { readily available to all health care professional }\end{array}$ & 5 & 3 \\
\hline 1.5 & & & Implement drug information connected with all infusion pump & 5 & 4 \\
\hline 2 & \multicolumn{5}{|c|}{ Pharmacy automation } \\
\hline 2.1 & \multirow{2}{*}{ Strategic Goal 3} & \multirow{2}{*}{$\begin{array}{l}\text { MM.31 } \\
\text { MM.36 }\end{array}$} & Implement automated dispensing cabinet & 4 & 3 \\
\hline 2.2 & & & Use electronic smart infusion pump for high alter medication & 5 & 5 \\
\hline 3 & \multicolumn{5}{|c|}{ Pharmacy human resources } \\
\hline 3.1 & \multirow{2}{*}{ Strategic goal 2} & \multirow{2}{*}{$\begin{array}{l}\text { MM.2 } \\
\text { MM.3 }\end{array}$} & Medication administration safety awareness session for health care professional & 5 & 5 \\
\hline 3.2 & & & Smart infusion pump safety awareness session for health care professional & 5 & 5 \\
\hline 4 & \multicolumn{5}{|c|}{ Pharmacy innovation and empowering culture } \\
\hline 4.1 & \multirow{2}{*}{ Strategic Goal 4} & \multirow{2}{*}{$\begin{array}{l}\text { MM.26 } \\
\text { MM.36 }\end{array}$} & Implement bar-coding system machines during medication administration & 5 & 4 \\
\hline 4.2 & & & Use premixed fixed concentration medication & 5 & 5 \\
\hline 5 & \multicolumn{5}{|c|}{ Guidelines and protocols } \\
\hline 5.1 & \multirow{2}{*}{ Strategic Goal 1} & \multirow{2}{*}{$\begin{array}{l}\text { MM.26 } \\
\text { MM.29 } \\
\text { MM.31 }\end{array}$} & Use fixed centration for all Intravenous medication & 5 & 4 \\
\hline 5.2 & & & Use fixed concentration of oral syrup and suspension medication & 5 & 3 \\
\hline 6 & \multicolumn{5}{|c|}{ Pharmacy risk management } \\
\hline 6.1 & \multirow{2}{*}{ Strategic goal 1} & \multirow{2}{*}{$\begin{array}{l}\text { MM.36 } \\
\text { MM.39 }\end{array}$} & Implement medication administration performance indicators & 5 & 4 \\
\hline 6.2 & & & Implement smart infusion pump performance indicators & 5 & 5 \\
\hline 7 & \multicolumn{5}{|c|}{ Pharmacy clinical audit } \\
\hline 7.1 & \multirow{3}{*}{ Strategic Goal 5} & \multirow{3}{*}{$\begin{array}{l}\text { MM.36 } \\
\text { MM.40 } \\
\text { MM.41 }\end{array}$} & $\begin{array}{l}\text { Annual survey of ISMP self-assessment of medication safety for all mass gathering } \\
\text { hajj hospitals }\end{array}$ & 5 & 5 \\
\hline 7.2 & & & Regular medication administration performance indicators & 5 & 4 \\
\hline 7.3 & & & Regular report of all smart infusion pump & 4 & 5 \\
\hline
\end{tabular}

pump for high alter medication implement bar-coding system machines during medication administration. For more detail recommendation as explored in Table 5.

\section{CONCLUSION}

Utilize the new technologies medication devices and a new formulation of fixed drug concentration prevent drug events and avoid the unnecessary economic burden on health care. The ISMP self-assessment medication safety is a useful tool to assess the safety of medicines devices. The authors highly recommended to new technologies drug devices with all related issues during mass gathering Hajj time. 


\section{ACKNOWLEDGEMENT}

I want to thank all directors of pharmacies at all hospitals in Makka region for their cooperation and filled the survey.

\section{CONFLICT OF INTEREST}

None

\section{ABBREVIATION USED}

GAPC: General administration of Pharmaceutical Care, CBAHI: Saudi Central Board for Accreditation for Health Care Institutions, MOH: Ministry of Health, ISMP: Institution Safe Medication Practice

\section{REFERENCES}

1. Khoja T, Neyaz Y, Qureshi N. Medication errors in primary care in Riyadh city, Saudi Arabia. East Mediterr Health J. 2011;17(2):156-9.

2. Dibbi H, Al-Abrashy H, Hussain W. Causes and outcome of medication errors in hospitalized patients. Saudi Med J. 2006;27(10):1489-92.

3. Al-Dhawailie A. Inpatient is prescribing errors and pharmacist intervention at a teaching hospital in Saudi Arabia. Saudi Pharm J. 2011;19(3):193-6.

4. Al-Jeraisy M, Alanazi M. Medication prescribing errors in a pediatric inpatient tertiary care setting in Saudi Arabia. BMC Res Notes. 2011;4(1):294.

5. Aboshaiqah AE. Barriers to Reporting Medication Administration Errors as Perceived by Nurses in Saudi Arabia. Middle-East J Sci Res. 2013;17(2):130-6.

6. Adult Parenteral Dilution Manual. 1st Ed. General Administration of Pharmaceutical care, MOH, Saudi Arabia; 2015. Available from: https:// www.researchgate.net/publication/281710454_Adults_Parenteral_Dilution_ Manual

7. Pediatrics Parenteral Dilution Manual. 1st Ed. General Administration of Pharmaceutical care, MOH, Saudi Arabia; 2015. Available from: https:// www.researchgate.net/publication/281710402_Pediatrics_Parenteral_
Dilution_Manual

8. Neonates Home Care Parenteral Dilution Manual. 1st Ed. General Administration of Pharmaceutical care, $\mathrm{MOH}$, Saudi Arabia; 2015. Available from: https://www.researchgate.net/publication/281710618_Neonates Home_Care_Parenteral_Dilution_Manual

9. Ahmed $\mathrm{S}, \mathrm{Al}$-Abbas $\mathrm{S}, \mathrm{Al}-\mathrm{Omran} \mathrm{A}$. Medication administration errors in Eastern Saudi Arabia. Saudi Med J. 2010;31(11):1257-9.

10. Aboshaiqah AE. Nurses' Perception of Medication Administration Errors. Am J Nurs Res. 2014;2(4):63-7.

11. Vaida AJ, Smetzer JL, Lamis RL, Cohen MR, Kenward K. Assessing the state of safe medication practices using the ISMP medication safety selfassessment ${ }^{\circledR}$ for hospitals: 2000 and 2011. Jt Comm J Qual Patient Saf. 2014;40(2):51-67.

12. Smetzer JL, Vaida AJ, Cohen MR, Tranum D, Pittman MA, Armstrong CW. Findings from the ISMP Medication Safety Self-Assessment $₫$ for Hospitals. Jt Comm J Qual Saf. 2003;29(11):586-97.

13. Ministry of Health. 1st Ed. Riyadh, Saudi Arabia: Ministry of Health, Saudi Arabia; 2011. Available from: http://sgsminsk.by/_/media/Global/Documents/ Technical Documents/Technical Datasheets/SGS-PCA-SA-Datasheet SFDA-A4-EN-11-V2.pdf

14. Neonates Parenteral Dilution Manual. 1st Ed. General Administration of Pharmaceutical care, MOH, Saudi Arabia; 2015. Available from: https:// www.researchgate.net/publication/281710411_Neonates_Parenteral_ Dilution_Manual

15. MOH. Ministry of Health Formulary. Off Heal Minist Advis Logist Cap Equipment. 2012; Available from http://www.moh.gov.sa/en/Portal/ WhatsNew/Documents/MOHF_DRUG_LIST_CD.pdf

16. Larsen GY. Standard Drug Concentrations and Smart-Pump Technology Reduce Continuous-Medication-Infusion Errors in Pediatric Patients. Pediatrics. 2005;116(1):e21-e25.

17. Irwin D, Vaillancourt R, Dalgleish D, Thomas M, Grenier S, Wong E, et al. Standard concentrations of high-alert drug infusions across pediatric acute care. Paediatr Child Health. 2008;13(5):371-6.

18. Murray KL, Wright D, Laxton B, Miller KM, Meyers J, Englebright J. Implementation of standardized pediatric i.v. Medication concentrations. Am J Heal Pharm. 2014;71(17):1500-8.

19. Jung B, Couldry R, Wilkinson S, Grauer D. Implementation of standardized dosing units for i.v. medications. Am J Health Syst Pharm. 2014;71(24):21538.

20. Lucas AT, Rowe E, Eckel SF. Determining the Need for Standardized Infusions and Concentrations at Hospitals within North Carolina. Hosp Pharm. 2016;51(3):237-45.

Cite this article as: Alomi YA, Khayat NAY, Baljoon MJ, Bamagaus YA, Jumah HMA. National Survey of Hospital Medication Safety Practice during Mass Gathering (Hajj-2016) In Makka, Saudi Arabia: Medication Administration . J Pharm Pract Community Med. 2017;3(4s):S22-S28. 